\title{
MEMÓRIA E NARRATIVAS (AUTO)BIOGRÁFICAS: A CONSTRUÇÃO DA IDENTIDADE DOCENTE DE PROFESSORES FORMADORES EM GEOGRAFIA
}

\author{
Memory and (self)biographical narratives: the construction of the teaching \\ identity of teaching teachers in Geography
}
Memoria y narrativas biográficas: la construcción de la identidad docente de profesores de enseñanza en Geografía

\author{
Victória Sabbado Menezes* \\ Roselane Zordan Costella** \\ * Doutoranda em Geografia da UFRGS \\ - vi145_sm@hotmail.com \\ ** Professora Pós-Graduação em Geografia da UFRGS \\ - professoracostella@gmail.com
}

\author{
Recebido em 07/04/2020. Aceito para publicação em 04/05/2020 \\ Versão online publicada em 04/07/2020 (http://seer.ufrgs.br/paraonde)
}

\section{Resumo:}

Este trabalho origina-se de uma tese de doutorado em andamento relacionada à linha de pesquisa em Ensino de Geografia. $O$ intuito da pesquisa consiste em analisar como as memórias de professores formadores de Geografia atuam sobre sua identidade docente e influenciam a formação dos licenciandos. Para tanto, será adotada a abordagem (auto)biográfica enquanto método. A metodologia assenta-se nas histórias de vida, de modo que a fonte de pesquisa serão as narrativas dos professores formadores de Geografia de uma universidade federal do estado do Rio Grande do Sul. A escolha pelas narrativas (auto)biográficas se justifica pelo entendimento de que 0 ato de narrar engendra um processo reflexivo, autoformativo e heteroformativo durante sua execução. As reflexões apresentadas neste trabalho dizem respeito somente à pesquisa teórica construída a partir de uma revisão bibliográfica concernente ao ensino de Geografia, formação docente e pesquisa (auto)biográfica, uma vez que a pesquisa de campo ainda está inacabada. A partir disso, considera-se a presença significativa do saber da tradição pedagógica nas memórias dos professores, o que exige sua problematização na formação inicial, de modo que pode ser desenvolvido por meio das narrativas (auto)biográficas, visto que são concebidas não somente como dispositivo metodológico, mas também como dispositivo formativo.

Palavras-chave: Narrativas (auto)biográficas. Formação docente. Geografia.

\begin{abstract}
:
This work is originated from an ongoing doctorate thesis related to the research line in Geography Teaching. Its purpose is to analyze how the memories of Geography teachers act on their teaching identity and influence the formation of undergraduates. Therefore, the (self)biographical approach will be adopted as a method. The methodology is based on life histories, so that the source of this research will be the narratives of the Geography teachers of a federal university of the state of Rio Grande do Sul. The choice of the (self)biographical narratives is justified by understanding that the act of narrating engenders a reflexive, selfforming and hetero-formative process during its execution. The reflections
\end{abstract}


presented in this paper concern only the theoretical research created from a literature review concerning the teaching of Geography, teacher training and (self)biographical research, once the field research is still unfinished. From that, it is considered the significant presence of the knowledge of the pedagogical tradition in the teachers' memories, which demands its questioning in the initial formation, which can be developed through the (self)biographical narratives, since they are conceived not only as methodological device, but also as a formative device.

Key-words: (Self)biographical narratives. Teacher formation. Geography.

\begin{abstract}
Resumen:
Este trabajo se origina en una tesis doctoral en curso relacionada con la línea de investigación en Enseñanza de Geografía. El objetivo de la investigación es analizar cómo los recuerdos de los profesores de educación en Geografía actúan sobre su identidad docente e influyen en la formación de los estudiantes de pregrado. Para esto, se adoptará el método (auto) biográfico como método. La metodología se basa en historias de vida, por lo que la fuente de la investigación serán las narraciones de los maestros que enseñan Geografía en una universidad federal en el estado de Rio Grande do Sul. La elección de las narrativas (auto)biográficas se justifica por la comprensión de que el acto de narrar engendra un proceso reflexivo, auto formativo y heteroformativo durante su ejecución. Las reflexiones presentadas en este trabajo se refieren solo a la investigación teórica construida a partir de una revisión bibliográfica sobre la enseñanza de la Geografía, la formación del profesorado y la investigación (auto) biográfica, ya que la investigación de campo aún no está terminada. A partir de esto, se considera la presencia significativa del conocimiento de la tradición pedagógica en los recuerdos de los docentes, lo que exige su problematización en la formación inicial, para que pueda desarrollarse a través de las narrativas (auto) biográficas, ya que se conciben no solo como dispositivo metodológico, pero también como dispositivo formativo.
\end{abstract}

Palabras-clave: (Auto)narraciones biográficas. Formación del profesorado. Geografía.

\title{
1. Introdução
}

O presente artigo resulta de um trabalho enviado e apresentado na III Semana Acadêmica dos Pós-Graduandos do Instituto de Geociências SAPIGEO da Universidade Federal do Rio Grande do Sul (UFRGS) realizado no ano de 2019. Sua exposição no evento possibilitou o diálogo com os colegas da pós-graduação em Geografia e em Geologia, o que desencadeou reflexões sobre as quais pretende-se aprofundar neste artigo. A pesquisa em questão trata-se de um recorte de uma tese de doutorado em construção do Programa de Pós-Graduação em Geografia da UFRGS, na linha de pesquisa em Ensino de Geografia. Esta teve seu início em março do ano de 2017 e tem sua finalização prevista para março do ano de 2021. Cabe esclarecer que esta investigação, orientada pela professora [omitido para avaliação], está vinculada a um grupo de pesquisa denominado "Autonarrativas e formação docente", coordenado pelo professor [omitido para avaliação].

ParaOnde!?, Porto Alegre, v.13, n.1, p.250-266, 2020.http://seer.ufrgs.br/paraonde 
Este artigo está organizado com base nas reflexões teóricas produzidas até o momento, de maneira que não conta com a pesquisa de campo. Logo, pauta-se em uma revisão bibliográfica concernente à temática central, qual seja: memórias e narrativas (auto)biográficas de professores formadores em Geografia. As afirmações aqui explicitadas não aborda a pesquisa de campo, tendo em vista que o material empírico foi produzido até o final do ano de 2019 e ainda não foi desenvolvida a fase de tratamento e análise dos dados.

Os eixos basilares da pesquisa são: ensino de Geografia, formação de professores e pesquisa (auto)biográfica. Desta forma, o objetivo geral visa analisar como as memórias de ensino de professores da Licenciatura em Geografia atuam sobre sua identidade docente e influenciam a formação dos licenciandos. Pretende-se investigar quais as memórias de ensino escolar e universitário os professores formadores carregam e como estas atuam sobre suas concepções epistemológicas e pedagógicas de Geografia e de Educação, bem como seus efeitos sobre suas práticas pedagógicas na licenciatura. Logo, parte-se do princípio de que tais memórias exercem influência na constituição do ser docente, acarretando em determinadas posturas no seu fazer pedagógico e, por consequência, agindo na formação dos acadêmicos, futuros professores de Geografia.

A investigação se justifica pelo fato de que, como aponta a literatura e as experiências profissionais da autora, ainda é hegemônico um ensino de Geografia escolar pautado na descrição, memorização e reprodução de conteúdos. Por outro lado, percebe-se que a maioria dos cursos de Licenciatura em Geografia do país, em termos de currículo e práticas, são orientados para o fortalecimento de uma Geografia Crítica e Humanista e um ensino construtivista. Sendo assim, surge um paradoxo: se a formação docente, na maioria dos casos, é voltada para uma determinada linha teóricometodológica, por que as práticas de ensino de Geografia no espaço escolar permanecem arraigadas a uma corrente de Geografia Tradicional, de Educação empirista e de pedagogia diretiva?

Diante desta inquietação, ampara-se em Tardif (2014) que preconiza que os saberes dos professores provêm de diversas fontes, de maneira que a formação inicial (licenciatura) corresponde a apenas uma destas. Logo, a formação docente ocorre ao longo da existência do sujeito nos mais variados espaços e nas relações com outros, não somente no âmbito da formação inicial e da carreira profissional. Atribui-se às vivências na condição de aluno na escola, onde o saber da tradição pedagógica é dominante, como um dos principais influenciadores na construção das concepções e das práticas dos sujeitos que se tornaram professores. A ressignificação destas memórias e sua implicação nas práticas docentes dos professores formadores referem-se ao cerne da discussão que se pretende empreender.

No que diz respeito aos objetivos específicos da tese, elencam-se os seguintes: analisar memórias e narrativas (auto)biográficas de professores formadores de Geografia a fim de investigar o processo de construção de sua identidade docente; identificar as percepções dos licenciandos acerca da formação inicial e de sua constituição docente; reconhecer como as narrativas

ParaOnde!?, Porto Alegre, v.13, n.1, p.250-266, 2020.http://seer.ufrgs.br/paraonde 
(auto)biográficas podem atuar na ressignificação de três Geografias: a primeira Geografia (grafia de si, corpo), a Geografia acadêmica e a Geografia escolar.

Tendo em vista a fase que se encontra a pesquisa, esta produção textual se dedicará a promover uma discussão teórica concernente ao papel da memória na constituição do imaginário docente e sua repercussão no processo de construção da identidade profissional. O suporte teórico para estas formulações assenta-se no campo da pesquisa (auto)biográfica em Educação, o qual orienta a linha de pensamento adotada, bem como os procedimentos metodológicos empregados. Sendo assim, a escolha pelas narrativas (auto)biográficas se justifica enquanto fonte de investigação, mas também por constituir um dispositivo formativo. Analisar memórias de professores por meio de narrativas (auto)biográficas possibilita discutir a problemática da formação docente, além de propiciar um processo autorreflexivo ao sujeito da pesquisa.

\section{Metodologia}

Com a finalidade de alcançar os objetivos propostos, adotou-se a abordagem (auto)biográfica enquanto método (NÓVOA; FINGER, 2014). Este é próprio do campo da pesquisa (auto)biográfica que tem suas origens ligadas à Escola de Chicago por volta da segunda década do século XX. Sua gênese está associada à intencionalidade de dar voz aos silenciados, aos esquecidos da história. Logo, surge a partir de questionamentos às dicotomias inerentes à racionalidade técnica hegemônica, a qual separa sujeito de objeto, indivíduo de sociedade, singular de universal, teoria de prática.

Cabe salientar que a pesquisa (auto)biográfica está associada ao campo das Ciências Humanas e Sociais e tem sido utilizada na Educação nas últimas três décadas (PASSEGGI; ABRAHÃO; DELORY-MOMBERGER, 2012). Esta perspectiva confere atenção ao sujeito, colocando-o como centro do processo de investigação. O sujeito é concebido como autor, ator e em constante devir. O foco de interesse volta-se às histórias de vida, as quais são expostas em forma de relatos orais ou escritos por meio de narrativas (auto)biográficas. Estas permitem que o narrador se perceba como sujeito de sua história.

Ao mesmo tempo que a pesquisa (auto)biográfica considera o indivíduo e sua história de vida como algo singular, não dispensa a relação com o universal. Ferrarotti (2014, p. 41) esclarece que:

Todas as narrações autobiográficas relatam, segundo um corte horizontal ou vertical, uma práxis humana. Ora, se 'a essência do homem [...] é, na sua realidade, o conjunto das relações sociais' (Marx, VI Tese de Feuerbach), toda a práxis humana individual é atividade sintética, totalização ativa de todo um contexto social. Uma vida é uma práxis que se apropria das relações sociais (as estruturas sociais) interiorizando-as e voltando a traduzi-las em estruturas psicológicas, por meio da sua atividade desestruturantereestruturante. Toda a vida humana se revela, até nos seus aspectos menos generalizáveis, como a síntese vertical de uma hsitória social. Todo o comportamento ou ato individual nos parece, até nas formas mais únicas, a síntese hrizontal de uma estrutura social.

ParaOnde!?, Porto Alegre, v.13, n.1, p.250-266, 2020.http://seer.ufrgs.br/paraonde 
O sistema social está presente nos comportamentos e ações individuais. A história da vida individual traz elementos para compreender o contexto social, de maneira que não é possível dissociar a individual do social, o singular do universal. Por conseguinte, a metodologia assenta-se nas histórias de vida, de modo que a fonte de pesquisa são as narrativas (auto)biográficas dos professores formadores de Geografia de uma universidade federal do estado do Rio Grande do Sul. Considera-se uma alternativa interessante para trabalhar com as memórias dos educadores por meio da explicitação das narrativas de si.

As narrativas (auto)biográficas, aqui entendidas como fonte de investigação e como dispositivos formativos, são elaboradas a partir de relatos do sujeito acerca de sua trajetória de vida, de formação e de atuação profissional. Narrar a si mesmo consiste em narrar sua história de vida, os caminhos trilhados, as experiências vivenciadas. As narrativas resgatam memórias do sujeito que revelam os percursos tomados ao longo da sua existência. Esta evocação de memórias está associada aos elementos que configuram sua identidade pessoal e profissional, as quais estão mutuamente implicadas.

Analisar narrativas (auto)biográficas docentes possibilita buscar a compreensão dos itinerários que atuam na formação do ser professor. Considera-se que a formação transcorre ao longo da existência a partir de diferentes vivências nos mais diversos espaços, os quais não se limitam às instituições escolar e universitária. Nesse sentido, as narrativas (auto)biográficas de professores facilitam o entendimento do processo de construção da professoralidade, o que também se vincula ao seu processo identitário. Para além disso, as narrativas possuem uma dimensão formativa ao próprio narrador, visto que "cria a memória entre passado e futuro, entre o fazer e o dizer. É uma prática de produção de si mesmo que contribui para que cada um 'tome em mãos' a própria vida. É asism que ela se torna formadora" (LANIBAYLE; POZZER; PASSEGGI, 2012, p. 65)

No que tange à maneira de organizar a pesquisa de doutorado, esta apresenta dois momentos: a revisão bibliográfica e a pesquisa de campo. A revisão bibliográfica diz respeito ao levantamento de bibliografias referentes aos principais eixos da pesquisa: Ensino de Geografia, Formação de Professores e Pesquisa (auto)biográfica. A pesquisa de campo foi realizada através de um questionário e entrevista narrativa (BERTAUX, 2010) com os professores formadores e grupo focal com acadêmicos licenciandos. $O$ questionário solicitou os dados biográficos dos sujeitos, como idade, curso, instituição e ano de formação, tempo de carreira, disciplinas ministradas na licenciatura. A entrevista narrativa foi elaborada a partir de um roteiro com questões orientadoras, as quais se dispuseram em três eixos temáticos: história de vida, memórias de ensino e formação-profissão. Já o grupo focal com os licenciandos também apresentou perguntas norteadoras a fim de provocar o diálogo relativo sobre a formação propiciada pela licenciatura, suas fragilidades e potencialidades, as mudanças necessárias e o olhar dos mesmos

ParaOnde!?, Porto Alegre, v.13, n.1, p.250-266, 2020.http://seer.ufrgs.br/paraonde 
para o processo de formação docente. Cabe esclarecer que o universo de pesquisa abrange oito professores da Licenciatura em Geografia e acadêmicos da mesma de uma universidade pública federal do Rio Grande do Sul.

Os professores formadores selecionados são aqueles que ministram as disciplinas específicas do curso e que não trabalham com as disciplinas de ensino de Geografia, mas lecionam na Licenciatura. Este critério se justifica pelo intuito de conhecer como esses professores, que não se dedicam à pesquisa em Ensino de Geografia, pensam a formação docente, o ensino e a Geografia escolar. Os acadêmicos serão dos mais variados semestres da licenciatura, mas com a condição de que já tenham cursado alguma disciplina que lhe tenha propiciado o contato com a escola e possam refletir, a partir de algumas experiências vividas em âmbito escolar, sua identidade docente e sua formação universitária.

Contudo, é preciso esclarecer que o presente artigo não discorre sobre os resultados da pesquisa, uma vez que esta não foi finalizada. O material levantado por meio dos questionários, entrevistas narrativas e grupo focal com os sujeitos da pesquisa ainda não foram analisados e interpretados. No momento que tal fase for realizada será utilizado o método de análise cunhado por Santamarina e Marinas (1994), conhecido como "compreensão cênica". O enfoque deste artigo, por sua vez, centra-se na pesquisa teórica desenvolvida pela revisão bibliográfica, cujo destaque encontra-se na problemática referente às memórias dos professores e suas implicações na identidade docente e atuação profissional na licenciatura. Tratam-se de reflexões que, amparadas nos pressupostos da pesquisa (auto)biográfica, propiciam (re)pensar a formação de professores e o ensino de Geografia.

\section{Memórias e imaginário docente}

Revisitar memórias significa buscar no baú íntimo de cada um os diversos acontecimentos, situações e vivências marcantes ao longo de sua caminhada de vida. Em se tratando de sujeitos professores, esta memória é de suma importância para identificar possíveis fatores que Ihe influenciaram na escolha da profissão. Compreender a vida em sua dimensão formativa remete à noção de que a docência não se constrói exclusivamente na formação universitária e no exercício da carreira nas instituições escolares. As representações e concepções pertinentes à profissão, bem como as práticas pedagógicas adotadas em sua ação docente também podem estar relacionadas a outras fontes relacionadas às singularidades de seus itinerários de vida.

Todos aqueles que escolheram serem professores tiveram a possibilidade de conviver com seu lócus de trabalho por muito tempo. De acordo com Kaercher (2014, p. 35), "hoje, tenho claro que aprendemos a ser professores desde que nos tornamos alunos, desde muito crianças, portanto". Estas representações acerca da docência e do papel docente são carregadas pelos sujeitos ao longo da vida. Trata-se de exemplos e modelos que foram criados nas mentes dos sujeitos durante o processo de escolarização, processo este que abrange mais de dez anos. Logo, o contato com o futuro

ParaOnde!?, Porto Alegre, v.13, n.1, p.250-266, 2020.http://seer.ufrgs.br/paraonde 
espaço de trabalho e a participação na sua dinâmica de funcionamento, ainda que de forma inconsciente e no papel de aluno, incide sobre a imagem que este sujeito cria sobre a profissão docente.

A trajetória de escolarização permite que o sujeito tenha um contato próximo com o professor, profissional que se constituirá futuramente. Evidente que a criança e o adolescente, em grande parte das vezes, ainda não têm sua escolha profissional definida e, mesmo que tenham o interesse de tornarem-se professores (o que é raro!) não possuem a consciência sobre os aprendizados relacionados à profissão que sua condição de alunos lhe permite. Contudo, é inegável que os professores são capazes de deixar marcas em seus alunos. Marcas que podem ser positivas, vistas como exemplo a ser seguido, ou negativas, internalizadas como exemplo do que não ser-fazer. Estas marcas são tão importantes, pois permanecem vivas nas memórias dos sujeitos e atuam sobre seu processo de construção identitária.

Nesse sentido, salienta-se que a identidade docente se constitui ao longo da existência, de modo que as memórias exercem uma influência significativa neste processo. Segundo Costella (2018, p. 54), percebe-se que o professor, apesar do contato com diferentes referenciais ao longo de sua formação, "no momento de sua prática volta a fazer o que realmente carrega em sua memória, mesmo que de forma obscura. Memória esta que está centrada na época em que aprendeu". Aqui está o cerne de uma problemática que se impõe como desafio ao ensino de Geografia e à formação de professores. Se os cursos de licenciatura em Geografia, sobretudo a partir da década de 70 do século $X X$, devido às mudanças provocadas pelo movimento de renovação no pensamento geográfico vigente, foram atingidos no sentido de repensar seus currículos em conformidade com a nova onda de discussões que se instaurava, por que as práticas escolares ainda estão atreladas às correntes mais antigas, como da Geografia Tradicional?

É digno de nota que o momento de efervescência teórico-metodológico no campo da Geografia ocorreu em paralelo a um movimento também implantado no campo da Educação, especialmente da Pedagogia. Logo, o movimento de Geografia Crítica brasileira carregava princípios que estavam em consonância com o movimento da Pedagogia Crítica. Tratava-se de um período que acompanhava as transformações do contexto sociopolítico do país. Entretanto, embora as discussões referentes à Geografia e ao ensino tivessem avançado em âmbito acadêmico, as mesmas tiveram (e ainda têm) dificuldades de atingir de forma concreta e completa as práticas efetivas dos professores do ensino básico, conforme aponta o estudo da tese de Kaercher (2004) acerca de como a Geografia Crítica alcançou o Ensino Fundamental e Médio no Brasil.

Ainda no contexto hodierno verifica-se o distanciamento entre o debate teórico engendrado no espaço acadêmico e os pressupostos que embasam as práticas de ensino em Geografia em âmbito escolar. Em pesquisa anterior da presente autora (omitido para avaliação, 2016), cuja dissertação de mestrado investigou as concepções teóricas e a epistemologia da prática de professores de Geografia do ensino básico e de acadêmicos concluintes da licenciatura

ParaOnde!?, Porto Alegre, v.13, n.1, p.250-266, 2020.http://seer.ufrgs.br/paraonde 
(futuros professores), constatou-se o pluralismo e a contradição epistemológica nos discursos e práticas dos sujeitos. Ainda que fosse possível observar algumas divergências entre os grupos de sujeitos (professores e licenciandos), o que se destacou na maioria foi a percepção de que embora alguns discursos revelassem concepções teóricas que se aproximam das linhas da Geografia Crítica e Humanista e da Educação construtivista, as práticas educativas apresentavam a predominância de características próprias da Geografia Tradicional e da epistemologia empirista de Educação. Aliado a isso, chamou a atenção que este enraizamento de práticas tradicionais e empiristas estava mais forte na ação pedagógica dos acadêmicos, futuros professores.

Diante disso, nota-se que o modelo hegemônico de ensino de Geografia, - qual ainda apresenta traços marcados pela descrição, reprodução, descontextualização dos fenômenos e pouca ação reflexiva, está vinculado à concepção empirista que se encontra naturalizada nas práticas docentes. De acordo com Becker (1993, p. 39):

\begin{abstract}
Pode-se afirmar que o empirismo é a forma que mais amplamente caracteriza a epistemologia do professor. Pode-se dizer, inclusive, que mesmo os docentes com posições aprioristas/inatistas ou que se aproximam de uma postura interacionista não conseguem superar totalmente sua epistemologia empirista. Numa palavra, todos os docentes são, pelo menos em algum grau, empiristas. Ela é, também, a postura mais claramente verbalizada; talvez por ser a que mais se aproxima do senso comum. Ou seja, é aquela que é professada aquém de qualquer questionamento.
\end{abstract}

Isto posto, torna-se claro que os cursos de formação inicial de professores não têm apresentado resultados positivos no que tange à desconstrução do empirismo inerentes às práticas docentes. Mesmo que seus currículos estejam estruturados com base em uma fundamentação teóricoepistemológica coerente aos princípios construtivistas e de uma Geografia Crítica e/ou Cultural, os egressos chegam nas salas de aula para dar início à sua carreira profissional e, em sua maioria, desenvolvem práticas educativas amparadas nas vertentes tradicionais de Geografia e de Educação.

Frente a este quadro do ensino de Geografia e da formação inicial docente, o desafio que se coloca reside na investigação dos possíveis elementos que atuam sobre a formação do professor e que ultrapassam o poder de influência dos cursos de licenciatura. Para tanto, o presente artigo se pauta na pesquisa (auto)biográfica, em termos teóricos e metodológicos, por considerar que esta possibilita uma chave analítica e compreensiva para a problemática em discussão. Esta perspectiva contribui para o esclarecimento e enfrentamento deste desafio na medida em que defende uma concepção mais ampla e complexa de formação, superando a visão própria do paradigma da ciência moderna alicerçado na racionalidade técnica.

É preciso esclarecer que este caminho teórico aqui adotado representa uma possibilidade, dentre outras que podem ser utilizadas para pensar a temática em questão. Não significa que esta é a única e/ou a mais correta, mas se trata de uma opção teórica que vai ao encontro da linha de pensamento que se defende no que diz respeito à formação docente em Geografia. O que se

ParaOnde!?, Porto Alegre, v.13, n.1, p.250-266, 2020.http://seer.ufrgs.br/paraonde 
quer enfatizar é que o olhar analítico propiciado pela abordagem (auto)biográfica é relevante pelas potencialidades que apresenta ao propor uma outra epistemologia, distinta da predominante nos cursos de formação de professores. Segundo Bragança (2016, p. 336), esta perspectiva abrange "uma epistemologia que abriga um objetivo libertador/emancipador".

Esta epistemologia confere atenção ao singular, mas também estabelece a articulação com o plural, uma vez que as trajetórias de vida do sujeito são relevantes para compreender o itnerário social e histórico. Sendo assim, há uma reversibilidade na posição do sujeito. Este é o centro do processo, é o protagonista, o sujeito de sua história. As narrativas (auto)biográficas são narrativas de si, dos seus percursos de vida. Por meio da perspectiva (auto)biográfica, a qual abarca uma outra epistemologia, há também outra noção de formação, distintas das predominantes.

O que se observa nos cursos de formação de professores é a vigência de uma concepção de formação que parte do exterior em direção ao sujeito, além de ocorrer através de um ambiente institucional. Ou seja, é a escola que forma o sujeito cidadão, a universidade que forma professores. Ou ainda 0 próprio exercício profissional nas salas de aula escolares também contribui na formação dos professores. Esta é uma visão mais restringida, pois desconsidera a importância que outros espaços e relações significam para o processo de constituição do ser docente. Além disso, a figura do professor é entendida mais como um produto do que como produtor de saberes acerca da profissão. São as universidades e escolas, por intermédio de seus currículos, práticas e experiências, que ensinam os conhecimentos profissionais aos docentes, conforme esta linha de raciocínio que se quesitona.

A abordagem (auto)biográfica não nega, tampouco desvaloriza, os espaços escolar e universitário como ambientes formativos e de aprendizagem. Todavia, entende que a vida como um todo é formativa ao sujeito, de modo que o processo existencial de cada um possui singularidades que se reverberam sobre seu processo identitário e marcam o seu ser-fazer docente. Segundo Souza (2006, p. 16), a narrativa propicia um conhecimento de si, no qual "inscreve-se como um processo de formação porque remete o sujeito numa pluralidade sincrônica e diacrônica de sua experiência, frente à análise de seus percursos de vida e de formação". Dessa maneira, esta outra noção de formação desloca as instituições e coloca o sujeito no lugar central, tendo em vista que é a partir da interação com diferentes esferas da vida que o sujeito de forma. Por isso, considera-se também o papel formativo de outros espaços, como aqueles que envolvem relações com a família, com amigos, com movimentos sociais, com sindicatos, entre outros.

A virada epistemológica ocorre devido a mudança da ideia de "formar" pela noção de "formar-se". É o sujeito que se forma por meio de um processo individual e autônomo mediado pela relação com os outros e com o ambiente. Esse processo se dá no decorrer da existência, o que abrange transformações, diversas experiências, contextos e relações. Nóvoa (2014) tece críticas ao modelo escolarizante atrelado a uma formação institucionalizada que se caracteriza por tempos próprios e espaços específicos. Para o autor, trata-se

ParaOnde!?, Porto Alegre, v.13, n.1, p.250-266, 2020.http://seer.ufrgs.br/paraonde 
de uma lógica de formação ultrapassada, pois esta é orientada por uma visão desenvolvimentista, a qual privilegia a ideia de progresso e perspectiva futura. Nóvoa (2014, p. 154) esclarece que:

\begin{abstract}
A abordagem biográfica reforça o princípio segundo o qual é sempre a própria pessoa que se forma e forma-se à medida que elabora uma compreensão sobre o seu percurso de vida: a implicação do sujeito no seu próprio processo de formação torna-se assim inevitável. Desse modo, a abordagem biográfica deve ser entendida como uma tentativa de encontrar uma estratégia que permita ao indivíduo-sujeito tornar-se ator do seu processo de formação, por meio da apropriação retrospectiva do seu percurso de vida.
\end{abstract}

Em contraposição à visão de formação pautada no desenvolvimento e no progresso, a perspectiva (auto)biográfica ampara-se na dimensão retrospectiva-prospectiva, o que configura o balanço de vida. A inter-relação temporal do passado, presente e futuro é manifestado na narrativa (auto)biográfica. Parte-se do pressuposto de que o projeto de si, o que o sujeito almeja ser e tornar-se vincula-se à imagem que o mesmo tem de si no momento presente, a qual relaciona-se à ressignificação atual do seu passado. Isso quer dizer que se o processo formativo se desenvolve no decurso de uma vida, o sujeito se constrói e se projeta enquanto pessoa e professor a partir de suas vivências passadas, para as quais são atribuídos sentidos e significados no momento presente e encaminham determinadas perspectivas. Conforme Delory-Momberger (2014, p. 315), o projeto de si está ligado ao poder-saber fornecido pela formulação da narrativa (auto)biográfica, o que faz com que aquele que "formando a história de sua vida, se forma a si mesmo, deve permitir-lhe agir sobre si mesmo e sobre as estruturas sócio-históricas nas quais ele evolui, dando-lhe os meios de inserir sua história no sentido e na finalidade de um projeto".

Destarte, as memórias estão no cerne de toda narrativa (auto)biográfica. Não é possível narrar sua história de vida sem recorrer ao passado e evocar memórias. Estas são de suma importância no âmbito da pesquisa em formação docente na medida em que revelam os percursos formativos do sujeito. Atribuise neste artigo um destaque para as memórias dos professores por entender que estas têm um poder explicativo para a questão-problema referente às principais fontes dos saberes-fazeres docentes e sua incidência sobre a identidade profissional. Salienta-se que resgatar as memórias dos professores possibilita que as mesmas sejam problematizadas e refletidas. Tarefa esta, cabe assinalar, que não é comum de ser realizada nas licenciaturas.

O que se percebe na maioria dos cursos de formação docente, assentados no paradigma da racionalidade técnica, é a consideração de que serão preparados futuros profissionais docentes a partir do momento que ingressam na licenciatura. Os saberes experienciais e/ou do senso comum anteriores são relegados a um plano secundário. No entanto, os sujeitos não são uma folha de papel em branco pronta para ser escrita quando iniciam a formação inicial. Cada um traz uma bagagem única, repleta de peculiaridades provenientes das trilhas percorridas até o momento. Estas trilhas compõem sua caminhada maior de vida, a qual é, por excelência, formativa. Logo, neste

ParaOnde!?, Porto Alegre, v.13, n.1, p.250-266, 2020.http://seer.ufrgs.br/paraonde 
processo criam-se modelos, representações e concepções sobre a docência, a Geografia, o ensino.

Problematizar as memórias de escola, por exemplo, podem acarretar na desconstrução de representações e ideias pré-estabelecidas que estavam consolidadas nas mentes dos sujeitos. Ao desconstruir estas representações, as quais orientam a conduta dos sujeitos professores, tem-se o ponto de partida para a transformação de suas práticas pedagógicas. As memórias dos professores são pontos delicados e que merecem investigação. Estas abarcam muito do que é estabelecido como referencial para o seu exercício docente. A narrativa (auto)biográfica traz à tona memórias que somente são enunciadas, pois apresentam significado no momento presente. Se não têm importância durante a ação narrativa, não são buscadas e expostas.

De acordo com Cunha (2012, p. 101), "o exercício de desvelamento que caracteriza a pesquisa autobiográfica fundamenta-se na memória. A memória assinala a nossa singularidade, direcionando as possibilidades de ser e fazer". A articulação passado, presente e futuro por meio da enunciação de memórias não traz apenas possíveis explicações para o que se é e como se é enquanto sujeito, mas também engendra possibilidades de ser. As memórias, ao serem relatadas, trazem elementos que dizem respeito à maneira como o sujeito se enxerga, visto que as narrativas resultam de um processo de seleção de memórias e de esquecimentos. A produção de narrativas (auto)biográficas consiste, portanto, numa ação do sujeito sobre si mesmo por meio da exposição de determinados fatos e acontecimentos rememorados conforme 0 contexto e os interesses do momento.

Pode-se afirmar que a narrativa possibilita a expressão de memórias, as quais não são contadas de maneira fiel. Toda memória resgatada passa por um processo de ressignificação no momento presente, ainda que de forma inconsciente. Dessa maneira, a memória refere-se a uma interpretação do vivido e, ao ser narrada, realiza-se uma nova interpretação que está associada ao tempo presente e às perspectivas de futuro. Por isso toda a narrativa (auto)biográfica apresenta uma certa medida de ficção e de criação, resultante dos processos interpretativos e da memória que necessariamente é reconfigurada. Isso não quer dizer que a pesquisa (auto)biográfica é frágil cientificamente, pois, de acordo com sua vertente epistemológica, a verdade em si não importa. O que interessa é a verdade do sujeito e para o sujeito. $\mathrm{Na}$ narrativa (auto)biográfica, o narrador é o sujeito de sua história e o que interessa refletir é sobre o seu relato, a representação de si. Este é o caminho que possibilita o autoconhecimento e, por consequência, o questionamento concernente ao vínculo entre o eu pessoal e o eu profissional.

Nesse sentido, busca-se em Candau (2016) o conceito de "metamemória" para embasar as considerações teóricas no que tange à noção de memória presente em narrativas (auto)biográficas. O autor classifica a existência de três dimensões da memória: a protomemória ou memória de baixo nível, a memória de alto nível e a metamemória. A primeira é uma memória-hábito, inconsciente e podendo ser oriunda de transmissão social. A segunda é a memória da recordação de saberes, sensações, sentimentos. Já a

ParaOnde!?, Porto Alegre, v.13, n.1, p.250-266, 2020.http://seer.ufrgs.br/paraonde 
terceira, a metamemória, compreende a representação da memória. Nas palavras de Candau (2016, p. 23), "a metamemória, que é, por um lado, a representação que cada indivíduo faz de sua própria memória, o conhecimento que tem dela e, de outro, o que diz dela, [...]. A metamemória é, portanto, uma memória reivindicada, ostensiva".

Portanto, as narrativas (auto)biográficas revelam metamemórias, isto é, a interpretação das memórias resgatadas, a representação que se elabora sobre as mesmas. Isso torna o processo narrativo ainda mais complexo diante da presença forte da subjetividade do sujeito. A manifestação de metamemórias estão diretamente relacionadas à identidade do sujeito. Memória e identidade estão mutuamente implicadas, de modo que uma alimenta a outra. Segundo Passeggi, Abrahão e Delory-Momberger (2012, p. 29), "quer queiramos ou não, poder reabrir o passado e inventar o porvir, pela mediação da palavra, constituem a inefável condição biográfica do humano". Sem memória o sujeito não tem identidade. Assim, o sujeito não é.

As narrativas (auto)biográficas possibilitam ao sujeito o direito de ser pelo fato de expor suas memórias e identidades. A memória modela, formata e atua sobre a produção da identidade, assim como esta age sobre as memórias que devem ser privilegiadas, ou seja, orienta quais as metamemórias que melhor representam o sujeito conforme suas intenções. Deve-se deixar claro que a identidade é móvel, é fluida e, ao longo da existência, passa por constantes modificações. Torna-se mais apropriado referir-se às identitdades, no plural, visto que o sujeito não possui um identidade única e fixa, mas múltiplas identidades que a longo da trajetória de vida vão construindo o ser.

É digno de nota que a identidade pressupõe alteridade. O sujeito constrói suas identidades pelo modo como enxerga a si mesmo, como se representa e também a partir do outro. O olhar do outro interfere sobre as identidades assumidas pelo sujeito. Novamente enfatiza-se a dimensão individual-plural, singular-universal. O sujeito não está isolado do mundo, mas é parte constituinte da sociedade. Assim como é produto desta, também é produtor. É inegável que a constituição de si ocorra mediante a relação com o outro.

No que diz respeito à identidade docente, ratifica-se que a mesma está entrecruzada pela identidade pessoal. Souza e Almeida (2013, p. 47) preconizam que:

\begin{abstract}
Portanto, partimos do entendimento de que a(s) identidade(s) docente(s) é/são dimensionada(s) pela pluralidade de vivências e experiências cotidianas construídas e constituídas em um processo multifacetado e multirreferencial que se alarga e se desenvolve a partir das mediações entre o 'eu pessoal' e o 'eu profissional' com a complexidade do contexto sociocultural e político-ideológico.
\end{abstract}

Se as memórias configuram identidades e, de forma específica, as identidades docentes, por que estas não são questionadas e/ou problematizadas no âmbito da formação inicial? A licenciatura representa 0 primeiro momento em que a profissão docente será pensada e refletida a partir de uma fundamentação teórica. É quando os acadêmicos, futuros professores,

ParaOnde!?, Porto Alegre, v.13, n.1, p.250-266, 2020.http://seer.ufrgs.br/paraonde 
entram em contato com os conhecimentos científicos e discutem a docência por meio da aprendizagem de teorias e métodos. Contudo, esta inserção no mundo acadêmico e o preparo direcionado ao mundo profissional necessita que as representações anteriores provenientes de suas crenças, experiências e opiniões sejam consideradas. É no momento da formação inicial, pelo fato de amparar-se em referenciais teóricos, que se têm argumentos para pôr em questão as representações relativas à docência que os sujeitos trazem consigo.

Nessa linha de pensamento, salienta-se a importância de discutir as memórias de ensino, pois são potentes ao orientar o fazer docente e gerar implicações na identidade profissional. Indaga-se: por que estas memórias, que predominantemente assentam-se no saber da tradição pedagógica, seguem vivas e em permanente difusão? Com aporte teórico em Halbwachs (2006) estas memórias ainda fortemente presentes nas mentes dos sujeitos se explicam, pois não se referem somente às memórias individuais. As mesmas constituem o que o autor nomeia de memória coletiva, uma vez que faz parte de um imaginário social.

A memória individual e a memória coletiva se interpenetram, porém são diferentes. Cada uma percorre o seu caminho, ainda que possam se cruzar em determinados pontos da trajetória. No tocante à discussão acerca da formação docente é importante analisar a relação entre memória individual e memória coletiva. Segundo o autor, a memória individual, "para confirmar algumas de suas lembranças, para torná-las mais exatas, e até mesmo para preencher algumas de suas lacunas, pode se apoiar na memória coletiva, nela se deslocar e se confundir com ela em alguns momentos" (HALBWACHS, 2006, p. 72). Ainda que a memória individual seja do sujeito, na sua ação de rememorar precisa recorrer à alguns pontos de referência que são determinados pela sociedade.

A trama tecida entre memória individual e coletiva justifica a criação de um imaginário sobre a docência. As memórias que os professores carregam sobre seu tempo de escola na condição de alunos se assemelham. São comuns os tipos de aula, os modelos de ensino, a maneira de relação professor-aluno, as formas de avaliação, a dinâmica de funcionamento da escola. Ainda que existam exceções, os sujeitos foram formados por um processo de escolarização semelhante, o qual deixou marcas profundas nas suas concepções de escola, de ensino e de formação. Assim, afirma-se que a memória coletiva legitima memórias individuais e compõe um imaginário docente. Imaginário este que está consolidado, pois resulta de um conjunto de discursos e práticas que vêm sendo reproduzidos ao longo de séculos.

Cabe esclarecer que de forma nenhuma se entende que a Educação está estagnada. É evidente que mudanças e avanços se procederam com o passar das décadas e de forma paralela às transformações sociais, políticas, econômicas e culturais. Entretanto, aponta-se para a questão de que novas roupagens, como a inserção de novas tecnologias no ensino e novas metodologias, por exemplo, provocaram poucos efeitos na essência, isto é, na epistemologia do modelo de ensino vigente. Verifica-se um imaginário docente

ParaOnde!?, Porto Alegre, v.13, n.1, p.250-266, 2020.http://seer.ufrgs.br/paraonde 
ainda atrelado às concepções mais tradicionais de ensino. Diante disso, propõe que a pesquisa (auto)biográfica seja introduzida nos cursos de formação de professores.

A construção, socialização e escuta de narrativas (auto)biográficas possibilitam a apresentação para si e para o outro dos seus itinerários de vida, de formação e de profissão. Resgatar estes itinerários pressupõe revelar metamemórias. A exposição destas metamemórias, que abrangem as crenças e representações dos sujeitos sobre a profissão docente, é condição necessária para que sejam analisadas e atravessadas por um processo reflexivo. Por conseguinte, as narrativas (auto)biográficas acarretam um processo de caminhar para si, como denomina Josso (2002). Conforme a autora:

\begin{abstract}
O processo do caminhar para si apresenta-se assim como um projeto, um projeto à escala de uma vida, cuja atualização consciente passa, em primeiro lugar, pelo projeto de conhecimento daquilo que somos, daquilo que pensamos, daquilo que fazemos, daquilo que valorizamos e daquilo que desejamos na nossa relação conosco próprios, com os outros, com o meio humano e natural. (JOSSO, 2002, p. 43)
\end{abstract}

Caminhar para si é ir ao seu encontro, é buscar o seu interior, é resgatar suas memórias significativas. Caminhar para si coloca o sujeito em um trânsito entre passado, presente e futuro. Trata-se de uma busca ontológica que provoca o sujeito a pensar os seus modos de ser, estar e fazer no mundo. Da mesma forma, permite que o professor busque a aproximação com a raiz de suas concepções e suas práticas de ensino, bem como vislumbrar seus modos de vir-a-ser. O sujeito, nesta perspectiva, está em constante devir e, ao narrar suas trajetórias de vida, se coloca aberto para possíveis mudanças e novos aprendizados.

Problematizar suas memórias de ensino e buscar referenciais que the propiciem uma clareza sobre 0 processo de construção da sua professoralidade instigam o exercício autônomo do sujeito no seu processo formativo. A consciência de si e de sua ação pedagógica conferem legitimidade aos seus modos de atuação docente. Desse modo, é imprescindível que o imaginário docente seja discutido no interior das licenciaturas, pois produz significados e exerce influência no fazer pedagógico dos professores. Fica clara a necessidade da pesquisa não somente com os professores do ensino básico, mas também com os professores formadores da licenciatura. Estes possuem relevância na medida em que por meio de seus discursos e práticas podem reforçar representações do imaginário docente arraigadas ao modelo tradicional de ensino, como também podem, por outro lado, questionar estas representações e desencadear discussões fundamentadas teoricamente acerca da constituição do ser docente.

Atribui-se à construção de narrativas (auto)biográficas nos cursos de formação inicial, tanto por seu caráter metodológico, quando por sua natureza (auto e hetero) formativa, uma possibilidade viável de (re)pensar os processos de formação docente. Trata-se de uma abordagem regida por outra epistemologia e por outra concepção de formação, distintas das

ParaOnde!?, Porto Alegre, v.13, n.1, p.250-266, 2020.http://seer.ufrgs.br/paraonde 
predominantes. Caracteriza-se por uma outra forma de pensar a constituição da identidade docente, ao considerar a trajetória de vida atrelada ao processo identitário. Se o eu pessoal é indissociável ao eu profissional, por que não resgatar as memórias marcantes dos percursos formativos ao longo da existência para buscar a compreensão de como se constrói professor?

\section{Considerações Finais}

Analisar as memórias e representações que permeiam o espaço da formação inicial é fundamental para identificar as concepções de ensino, de Geografia e de Educação que estão sendo fortalecidas na mente dos educadores e que terão implicações em seu fazer pedagógico. Esclarecer os significados construídos acerca da docência em Geografia compreende um caminho possível para a compreensão dos pilares que sustentam as práticas de ensino e para a elaboração de propostas que busquem mudanças que atinjam a raiz da problemática. Evidentemente que as tensões existentes nos processos formativos não serão superadas em sua totalidade, porém esta perspectiva de análise pode clarificar alguns pontos encobertos e apontar alternativas que visem à qualificação da formação inicial. Portanto, a aproximação e o contato com os professores formadores e com os graduandos são importantes para o entendimento da realidade vivenciada neste processo de formação.

Dessa maneira, não se pode questionar a postura dos licenciandos e futuros professores do ensino básico sem voltar o olhar aos professores formadores. Torna-se necessário que as pesquisas voltem-se para a formação docente, com ênfase nas práticas de ensino de professores formadores. É preciso que estes façam uma autoavaliação, uma autocrítica e uma autorreflexão. Não basta que a licenciatura seja composta por ótimos geógrafos; é premente possuir bons professores. Nesse sentido, os princípios que regem a atuação docente nos cursos de graduação de formação docente devem ser questionados.

Por conseguinte, a discussão aqui empreendida encontra-se no hiato entre o que o professor formador narra sobre sua trajetória formativa e sua identidade docente e o que vai se refletir no aluno, futuro professor. Localiza-se no entre-lugar, tendo em vista que as formulações teóricas e reflexões que se pretende propor situam-se entre a universidade (licenciatura) e a escola. $O$ intuito mais amplo da investigação, assentada na pesquisa (auto)biográfica, reside em ressignificar três dimensões, isto é, três Geografias: a primeira Geografia, a Geografia escolar e a Geografia acadêmica. Salienta-se que a narrativa (auto)biográfica provoca a autorreflexão do sujeito professor formador (primeira Geografia), o que poderá desencadear mudanças nas suas concepções e no seu fazer pedagógico na formação inicial (Geografia acadêmica), produzindo reflexos sobre a formação dos futuros professores que serão os responsáveis pelo ensino de Geografia na escola (Geografia escolar). Portanto, alternativas e idealizações no tocante à formação de professores não faltam. Torna-se premente concretizar tais ideias com vistas a conferir novos sentidos e significados à formação docente e ao ensino de Geografia.

ParaOnde!?, Porto Alegre, v.13, n.1, p.250-266, 2020.http://seer.ufrgs.br/paraonde 


\section{Referências}

BECKER, Fernando. A epistemologia do professor: o cotidiano da escola. 10. Ed. Petrópolis, RJ: Vozes, 1993.

BERTAUX, Daniel. Narrativas de vida: a pesquisa e seus métodos. Tradução Zuleide Alves Cardoso Cavalcante, Denise Maria Gurgel Lavallée. Natal, RN: EDUFRN; São Paulo: Paulus, 2010.

BRAGANÇA, Inês Ferreira de Souza. A formação de professores em trabalho apresentados no Congresso Internacional de Pesquisa (auto)biográfica. In: ABRAHÃO, Maria Helena Menna Barreto; FRISON, Lourdes Maria Bragagnolo; BARREIRO, Cristhianny Bento. (Orgs.). A nova aventura (auto)biográfica: tomo I. Porto Alegre: EDIPUCRS, 2016. P. 321-340.

CANDAU, Joel. Memória e identidade. Tradução Maria Letícia Ferreira. 1. Ed. 3aㅡ reimpressão. São Paulo: Contexto, 2016.

COSTELLA, Roselane Zordan. Espaços ausentes e não inexistentes na Geografia escolar. In: CASTROGIOVANNI, Antonio Carlos (Orgs. et. al.). Movimentos para ensinar geografia - oscilações. Goiânia: C\&A Alfa Comunicação, 2018. P. 47-59.

CUNHA, Jorge Luiz da. Pesquisas com (auto)biografias: interfaces em tempos de individualização. In: ABRAHÃO, Maria Helena Menna Barreto; PASSEGI, Maria da Conceição (Orgs.). Dimensões epistemológicas e metodológicas da pesquisa (auto)biográfica: Tomo I. Natal: EDUFRN; Porto Alegre: EDIPUCRS; Salvador: EDUNEB, 2012. P. 95-113.

DELORY-MOMBERGER, Christine. As histórias de vida: da invenção de si ao projeto de formação. Natal: EDUFRN; Porto Alegre: EDIPUCRS; Brasília: EDUNEB, 2014.

FERRAROTTI, Franco. Sobre a autonomia do método biográfico. In: NÓVOA, Antonio; FINGER, Mathias (Org.). O método (auto)biográfico e a formação. Trad. Maria Nóvoa. 2 ed. Natal, RN: EDUFRN, 2014. P. 29-55.

HALBWACHS, Maurice. A memória coletiva. Tradução de Beatriz Sidou. São Paulo: Centauro, 2006.

JOSSO, Marie-Christine. Experiências de vida e formação. Lisboa: Educa, 2002.

KAERCHER, Nestor André. A Geografia escolar na prática docente: a utopia e os obstáculos epistemológicos da Geografia Crítica. Tese (Doutorado em Geografia Humana) FFLCH, USP, São Paulo, 2004.

KAERCHER, Nestor André. Se a geografia escolar é um pastel de vento o gato come a geografia crítica. Porto Alegre: Evangraf, 2014.

LANI-BAYLE, Martine; POZZER, Albino; PASSEGGI, Maria da Conceição. Narrativas de vida: motivos, limites e perspectivas. In: PASSEGI, Maria da Conceição; ABRAHÃO, Maria Helena Menna (Orgs.). Dimensões epistemológicas e metodológicas da pesquisa (auto)biográfica. Tomo II

ParaOnde!?, Porto Alegre, v.13, n.1, p.250-266, 2020.http://seer.ufrgs.br/paraonde 
Natal: EDUFRN; Porto Alegre: EDIPUCRS; Salvador: EDUNEB, 2012. P. 5978.

MENEZES, Victória Sabbado. Geografia escolar: as concepções teóricas e a epistemologia da prática do professor de Geografia. 204 f. Dissertação (Mestrado em Geografia) - Programa de Pós-Graduação em Geografia Instituto de Geociências, Universidade Federal do Rio Grande do Sul, Porto Alegre, 2016.

NÓVOA, Antonio; FINGER, Mathias (Org.). O método (auto)biográfico e a formação. Trad. Maria Nóvoa. 2 ed. Natal, RN: EDUFRN, 2014.

NÓVOA, António. A formação tem que passar por aqui: as histórias de vida no Projeto Prosalus. In: NÓVOA, Antonio; FINGER, Mathias (Org.). O método (auto)biográfico e a formação. Trad. Maria Nóvoa. 2 ed. Natal, RN: EDUFRN, 2014. P. 143-175

PASSEGGI, Maria da Conceição; ABRAHÃO, Maria Helena Menna Barreto; DELORY-MOMBERGER, Christine. Reabrir o passado, inventar o devir: a inenarrável condição biográfica do ser. In: PASSEGGI, Maria da Conceição; ABRAHÃO, Maria Helena Menna (Orgs.). Dimensões epistemológicas e metodológicas da pesquisa (auto)biográfica: Tomo II. Natal: EDUFRN; Porto Alegre: EDIPUCRS; Salvador: EDUNEB, 2012. P. 29-57.

SANTAMARINA, Cristina; MARINAS, José Miguel. Historias de vida y historia oral. In: DELGADO, Juan Manuel; GUTIÉRREZ, Juan. Métodos y técnicas cualitativas de investigación en ciencias sociales. Madrid: Síntesis, 1994. P. 257-285.

SOUZA, Elizeu Clementino de. 0 conhecimento de si: estágio e narrativas de formação de professores. Rio de Janeiro: DP\&A; Salvador: UNEB, 2006.

SOUZA, Elizeu Clementino de; ALMEIDA, Joselito Brito. Memórias de educadores baianos: semelhanças e diferenças na constituição da vida na/da escola. In: SOUZA, Elizeu Clementino de; PASSEGI, Maria da Conceição; VICENTINI, Paula Perini (Orgs.). Pesquisa (auto)biográfica: trajetórias de formação e profissionalização. Curitiba, PR: CRV, 2013. P. 41-57.

TARDIF, Maurice. Saberes docentes e formação profissional. 16. ed. Petrópolis: Vozes, 2014.

ParaOnde!?, Porto Alegre, v.13, n.1, p.250-266, 2020.http://seer.ufrgs.br/paraonde 